\title{
Somatostatin Octapeptide Inhibits Cell Invasion and Metastasis in Hepatocellular Carcinoma Through PEBP1
}

\author{
Chuan-Zhong Huang a,e Ai-Min Huang ${ }^{b} \quad$ Jing-Feng Liu ${ }^{c, d} \quad$ Bin Wang,d \\ Ke-Can Lin ${ }^{c, d}$ Yun-Bin Yea,e \\ ammuno-Oncology Laboratory of Fujian Cancer Hospital, Fujian Medical University Cancer Hospital, \\ Fuzhou, Fujian, bDepartment of Pathology and Institution of Oncology, School of Basic Medical \\ Sciences, Fujian Medical University, Fuzhou, Fujian, 'Department of Hepatic Surgery, Liver Disease \\ Center of the First Affiliated Hospital of Fujian Medical University, Fuzhou, Fujian, ${ }^{d}$ The United \\ Innovation of Mengchao Hepatobiliary Technology Key Laboratory of Fujian Province, Mengchao \\ Hepatobiliary Hospital of Fujian Medical University, Fuzhou, Fujian, eFujian Provincial Key Laboratory of \\ Translational Cancer Medicine, Fuzhou, Fujian, China
}

\section{Key Words}

Hepatocellular carcinoma - Somatostatin octapeptide $\cdot$ Invasion and metastasis • PEBP1 $\bullet$ In vivo

\begin{abstract}
Background/Aims: Hepatocellular carcinoma (HCC) is a major threat to human health. The condition carries a high risk of death; $45 \%$ of new cases occur in China. Surgical resection is the first choice for treatment of HCC, but 30.9\% of patients experience recurrence within 6 months after the operation. To improve patient survival, we must determine how to reduce the probability of recurrence and metastasis and elucidate the underlying mechanism of disease. We therefore studied the effect of somatostatin octapeptide (octreotide) on the invasion and metastasis of HCC. Methods: The migration and invasion cytological tests were used to detect the effect of octreotide on liver cancer cells (SK-Hep-1 and HepG2). PEBP1 RNAi was used to knockdown expression. Invasion and metastasis were measured with transwell migration and wound-healing assays. Western blotting was used to detect changes in levels of PEBP1 and invasion pathway proteins after octreotide treatment. The effect of octreotide was studied in vivo by establishing a pulmonary metastasis model using SK-Hep-1 cells in nude mice. In-vivo bioluminescence imaging and hematoxylin and eosin staining of lung tissue were used to verify the results. Results: Increasing concentrations of octreotide were progressively more effective in halting the invasion and metastasis of liver cancer cells. Octreotide may upregulate PEBP1, TIMP-2, and E-cadherin while downregulating MMP-2 and Twist to inhibit cell invasion and metastasis. And downregulation of PEBP1 would also change the expression of MMP-2, TIMP-2 and Twist. The in-vivo experiments showed no cancer cell metastasis in 4 of the 6 mice in the octreotide-treatment group, while all of the mice in the control group
\end{abstract}


Huang et al.: Octapeptide Inhibits Metastasis of HCC by PEBP1

displayed pulmonary metastasis of human HCC cells. And the survival period of the mice in the octreotide-treatment group was significantly prolonged. Conclusions: Octreotide may weaken invasion and metastasis through the upregulation of PEBP1. Octreotide may reduce the risk of recurrence and metastasis after surgery for liver cancer.

\section{Introduction}

(C) 2018 The Author(s)

Published by S. Karger AG, Basel

Hepatocellular carcinoma (HCC) represents a major threat to human health. Each year, liver cancer develops in 626, 000 people and causes 598, 000 deaths [1]. HCC is the sixth leading cause of cancer and the third leading cause of death worldwide. Unfortunately, $45 \%$ of new cases occur in China [1,2].

Surgical resection is the first choice for treatment of HCC, but $30.9 \%$ of patients experience recurrence within 6 mo after surgery [3]. More than 70\% of HCC patients experience tumor recurrence or distant metastasis after operation or liver transplantation, and more than $90 \%$ of patients died because of HCC metastasis or recurrence. So, efforts to improve patient survival will require a better understanding of the underlying disease mechanism.

The effects of traditional treatment (e.g., surgical resection, radiotherapy, chemotherapy) on tumor recurrence and metastasis have been widely disputed. Chemotherapy and radiation were shown to increase TGF- $\beta$ levels in mice with breast cancer, leading to the migration of cancer cells to the lung. An antibody that decreased TGF- $\beta$ levels in vivo may limit cancer cell proliferation [4]. In addition to TGF- $\beta$, many chemical substances that play a role in immune signaling may inhibit the proliferation of cancer cells. Surgical interventions in patients with cancer, including biopsies, are commonly associated with increased concentrations of circulating tumor cells (CTCs) [5, 6]. High CTC levels are associated with an unfavorable prognosis in many cancers. These conclusions suggest that surgery, chemotherapy and radiotherapy may increase the risk of recurrence and metastasis. The "original" cancer cells may be able to inhibit the growth of other cancer cells; removal or killing of the original cancer cells may allow other non-detected cancer cells to grow. Researchers are investigating the use of auxiliary drugs combined with surgery or radiotherapy to reduce the risk of recurrence or tumor metastasis [6].

The somatostatin octreotide is a new, long-lasting octapeptide analog, which has been demonstrated to be safe for clinical use [7]. Somatostatin was first used in the treatment of neuroendocrine tumors, such as carcinoid, glucagonoma and gastrinoma. Because of its ability to inhibit the release of growth hormone, somatostatin has many inhibitory effects, such as reducing the secretory function of the digestive tract, reducing blood flow in internal organs (especially the liver), inhibiting inflammation, reducing portal pressure, and stabilizing cell membranes [8, 9]. In China, octreotide is used to ease endocrine tumorinduced symptoms, gastrointestinal fistula, severe pancreatitis, ulcer, and hemorrhage [10, 11]. Octreotide may inhibit cell activity by inhibiting intracellular ATP conversion, which reduces the consumption of ATP. In the context of hepatic ischemia-reperfusion, octreotide can enhance the compensatory ability of mitochondria, which accelerates ATP synthesis [12] and protects against reperfusion injury [13].

Our previous research suggested that octreotide may affect the invasion and metastasis of tumor cells. Therefore, a series of cytological experiments (e.g., transwell assay, scratch test) were used to study the effect of octreotide on cell migration and invasion in HCC cells. Western blotting was used to research the expression of PEBP1 and invasion related proteins after octreotide treatment.

\section{Materials and Methods}

Cell lines and chemicals

SK-Hep-1, HepG2, HuH7, MHCC-97H and SMMC-7721 human liver cancer cell lines were purchased from the Cell Bank of the Chinese Academy of Sciences (Shanghai, China). Octreotide (Sandostatin; $0.1 \mathrm{mg} /$ 


\section{Cellular Physiology Cell Physiol Biochem 2018;47:2340-2349 \begin{tabular}{l|l} 
and Biochemistry Published 1159/000491540 & $\begin{array}{l}\text { D) } 2018 \text { The Author(s). Published by S. Karger AG, Basel } \\
\text { www.karger.com/cpb }\end{array}$ \\
\hline
\end{tabular} \\ Huang et al.: Octapeptide Inhibits Metastasis of HCC by PEBP1}

$\mathrm{ml}$ ) was purchased from (Basel, Switzerland). All antibodies used for the experiment were purchased from Cell Signaling Technology (Boston, MA), except for PEBP1 antibody, which was purchased from Santa Cruz Biotechnology (Santa Cruz, CA). All chemicals were of analytical reagent grade. Water for all reactions, solution preparation and sample purification was double distilled.

\section{Cell culture}

SK-Hep-1 and HepG2 cells were maintained in MEM, HuH7 and MHCC-97H in DMEM, SMMC-7721 in 1640 , supplemented with $10 \%$ fetal bovine serum at $37^{\circ} \mathrm{C}$ in an atmosphere of $5 \% \mathrm{CO}_{2}$. Cells were grown to about $70 \%$ confluence in complete medium for corresponding experiments. Octreotide was diluted with MEM to $100 \mu \mathrm{g} / \mathrm{ml}$.

\section{Lentivirus infection}

Lentivirus carryingshRNAtargetinghuman PEBP1(shPEBP1) lentiviralvectors(GV248) wasconstructed by GeneChem (Shanghai, China). The targeted sequence was as follows: 3'-GGTCAACATGAAGGGCAAT-5'. Lentiviral virus preparation, infection and selection were performed according to the manufacturer's protocol. After 72 hours of virus infection, HepG2 clones designed to knockdown PEBP1 were observed by fluorescence microscopy to determine the efficiency of cell infection efficiency. Results were verified by western blotting.

\section{Transwell migration and invasion assays}

A transwell migration assay was performed using 8.0- $\mu \mathrm{m}$ pore insert 24-well plates (Becton Dickinson AG, Allschwil, Switzerland). Transwell chambers were pre-coated with $1 \mu \mathrm{g} / \mathrm{ml}$ fibronectin on the underside of the membrane. For the invasion assay, the $8.0-\mu \mathrm{m}$ pore-size membrane insert was coated with Matrigel (BD Biosciences) that had been diluted in medium (1:5 dilution). A total of $1 \times 10^{5}$ cells were plated in a 24-well cell culture insert in $100 \mu \mathrm{L}$ of FBS-free media. Inserts were then placed in the well with $500 \mu \mathrm{L}$ of $20 \%$ FBS containing media. After $24 \mathrm{~h}$, medium and cells in the culture insert were removed. Cells on the bottom side of the insert were methanol-fixed and stained with $0.1 \%$ crystal violet. Five random fields were selected; cells were counted at $100 \times$ magnification to determine the average number of cells in each insert.

Wound-healing assay

Cells were plated in 6-well plates in duplicate at approximately $80 \%$ confluence. The next day, a scratch wound was made through the center of each well using a 10- $\mu$ l pipette tip. Plates were washed with PBS, and fresh media were added to remove any loose cells. After $48 \mathrm{~h}$, cells were examined by light microscopy to assess resealing of the monolayer.

\section{Western blotting}

Proteins from the gels were transferred to an NC membrane for $1 \mathrm{~h}$ at $60 \mathrm{~V}$ in transfer buffer ( $48 \mathrm{mM}$ Tris, $39 \mathrm{mM}$ glycine and $20 \%$ methanol) at $4{ }^{\circ} \mathrm{C}$. The NC membrane was blocked for $2 \mathrm{~h}$ with $5 \%$ skim milk in TNT buffer (1.211 g Tris, $8.77 \mathrm{~g} \mathrm{NaCl}$, and $500 \mu \mathrm{L}$ Tween-20 in $1 \mathrm{~L} \mathrm{TNT}$, pH 7.0) at room temperature. After rinsing three times for 10 min with TNT buffer, the NC membrane was incubated with antibody in TNT buffer containing 5\% skim milk for $1 \mathrm{~h}$ at room temperature, with gentle shaking. The membrane was rinsed three times for 10 min with TNT buffer, then incubated with goat anti-rabbit horseradish peroxidase at a dilution of 1:1000 in TNT buffer containing 5\% skim milk for $1 \mathrm{~h}$, at room temperature. The membrane was then washed with TNT buffer. Results were visualized with SuperSignal West Pico kit (ThermoFish Scientific, USA) by Chemiluminescence Apparatus (Bio-rad, USA).

\section{Luciferase infection and establishment of stable clones}

Lentivirus-carrying luciferase vector was purchased from GeneChem. The virus was used to infect SKHep- 1 cells according to the manufacturer's protocol. After 72 hours of virus infection, SK-Hep-1 cells were passaged and cultured in MEM medium containing $2 \mu \mathrm{g} / \mathrm{ml}$ puromycin, for the selection of stable clones. To test the expression of luciferase, SK-Hep-1 cells were inoculated in the 96-well plate. Fluorescence was detected using a Luciferase Detection Kit with a multimode reader.

In-vivo nude mouse study

Female nude mice (BALB/c nu/nu; 4-6 weeks old, weight 18-20 g) were purchased from Fuzhou Minhou Laboratory Animal Co., Ltd. (Fuzhou, China). All experiments were approved by the Animal Ethics Committee of Fujian Medical University. To establish the pulmonary metastasis model, 12 mice were divided 


\section{Cellular Physiology Cell Physiol Biochem 2018;47:2340-2349 \begin{tabular}{l|l} 
DOI: 10.1159/000491540 & Ond Biochemistry \\
Publisned online: July 0y, 2018 & $\begin{array}{l}\text { 2018 The Author(s). Published by S. Karger AG, Basel } \\
\text { www.karger.com/cpb }\end{array}$
\end{tabular}}

Huang et al.: Octapeptide Inhibits Metastasis of HCC by PEBP1

into two groups and received $1 \times 10^{6}$ luciferase-infected SK-Hep- 1 cells per mouse in a final volume of $0.2 \mathrm{ml}$ PBS, by tail intravenous injection. Over the next 15 days, the mice in the octreotide-treatment (OT) group were injected with $120 \mu \mathrm{l}$ octreotide $(0.1 \mathrm{mg} / \mathrm{ml})$ subcutaneously every day; the control group received the same volume of PBS as control. Mouse body weight was measured once every 5 days. In-vivo optical imaging was performed 75 days later to observe tumor metastasis to the lung. Mice were then sacrificed for hematoxylin and eosin (H\&E) staining to confirm the results. After that, a same animal experiment was repeated and observed for 90 days. The death time of the two groups of mice was recorded, and then the survival curves of the two groups of mice were obtained by statistical analysis.

\section{In-vivo bioluminescence imaging and H\&E staining}

Bioluminescence imaging was used to evaluate cancer cells in the mice using the Xenogen in-vivo imaging system. Prior to imaging, mice were anesthetized with $10 \%$ chloral hydrate. Each mouse was injected intraperitoneally with $100 \mu \mathrm{l}$ luciferin $(25 \mathrm{mg} / \mathrm{ml}$, in-vivo grade, Promega, USA) and imaged $15 \mathrm{~min}$ later. The pseudocolor image from the active luciferase within each mouse was collected according to the following parameters: pixel width and height 1 , binning factor 4 , luminescent exposure $20 \mathrm{~s}$ and $\mathrm{f}$ number 8. Signal intensity was quantified using Living Image Software. To confirm tumor development in the lung, mice were sacrificed after whole-body imaging. The lung was isolated and imaged again, then fixed in $10 \%$ formalin for H\&E staining.

\section{Tissue protein extraction}

Weigh the lung tissue of mice and cut small pieces into the tubes. Put the mortar in ice before grinding, and adding a small amount of liquid nitrogen, and then transfer the lung tissues to the mortar. Continue to add liquid nitrogen, quickly mash and grind the tissues. Repeat the actions until the tissues became small white dry powder. Scraping dry powder into pre cooled protein extraction lysate containing protease inhibitors. The lysate was centrifuged by $14000 \mathrm{xg}$ for 15 minutes at $4^{\circ} \mathrm{C}$, and the supernatant immediately transferred into a new centrifuge tube and kept at $-80^{\circ} \mathrm{C}$ for use.

\section{Statistical analysis}

The data represent mean \pm SD from at least three independent experiments. All results were analyzed with Student's t-test. All data analyses were performed using the SPSS 20.0 statistical software package (IBM, Armonk, NY).

\section{Results}

\section{Effect of octreotide on liver cancer cell migration and invasion}

Transwell migration and wound-healing assays were used to measure the invasion and migration capacities of HepG2 and SK-Hep- 1 cells after octreotide treatment. Octreotide was administered at a concentration of 1,5 or $10 \mu \mathrm{g} / \mathrm{ml}$. The results of the transwell invasion and migration assays revealed a significant reduction in the migration of octreotide-treated liver cancer cells compared to controls (Fig. 1A and 1B). The results of the wound-healing assay revealed slower migration of octreotide-treated cells compared to controls (Fig. 1C). Results of both the transwell and wound-healing assays showed that invasion slowed when the concentration of octreotide reached $5 \mu \mathrm{g} / \mathrm{ml}$, then slowed further when the concentration reached $10 \mu \mathrm{g} / \mathrm{ml}$. Our findings suggest that octreotide may decrease the migratory and invasive potential of liver cancer cells.

\section{Primary mechanism of octreotide's effect on SK-Hep-1 migration and invasion}

To investigate the potential mechanism underlying octreotide's effect on the invasion and metastasis of HCC cells, western blotting was used to detect changes in the expression of molecules related to invasion and metastasis after exposure to the drug. The results of western blotting showed that octreotide $(10 \mu \mathrm{g} / \mathrm{ml})$ upregulated expression of TIMP-2 and E-cadherin, downregulated expression of MMP-2 and Twist, and caused no significant change in the expression of snail, slug, TIMP-1, or MMP-9 (Fig. 2A). Meanwhile, protein expression 
Fig. 1. Effects of octreotide on migration and invasion in HepG2 and SK-Hep-1 cells. A, Transwell invasion assay with octreotidetreated cells and control cells. Cells were incubated in transwell chambers and after 24 hours, cells at the bottom of the insert were stained and counted. B, Transwell migration assay with octreotidetreated cells and control cells. C, Migration of octreotide-treated cells and control cells was assessed by wound-healing assay. All experiments were repeated in triplicate. ${ }^{* *} \mathrm{P}<0.001$ vs. control group.

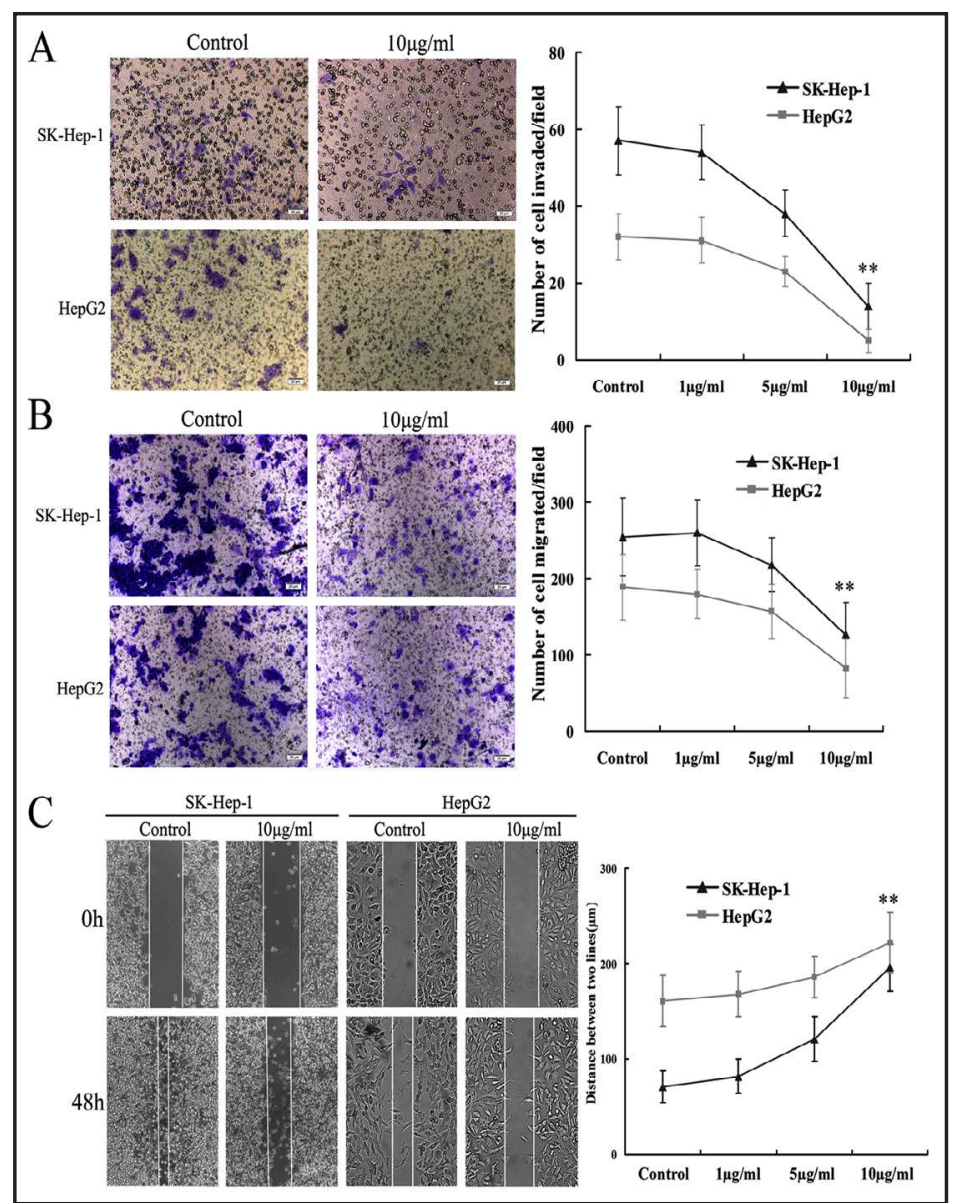

Fig. 2. Expression of migrationand invasion related proteins as measured by western blot in SK-Hep-1 cells. A, Expression of related proteins after octreotide treatment. Protein expression was similar in control cells and cells treated with a low concentration of octreotide. In cells treated with 10 $\mu \mathrm{g} / \mathrm{ml}$ octreotide, MMP-2 and Twist were downregulated, and TIMP-2 and E-cadherin were upregulated. B, Protein expression of MMP2, TIMP-2, Twist after treatment with shPEBP1. With PEBP1 being downregulated, MMP-2 and Twist were upregulated, and TIMP-2 was downregulated. $\beta$-actin was used as a loading control. All experiments were repeated in triplicate. ${ }^{* *} \mathrm{P}<0.001$ vs. control group.

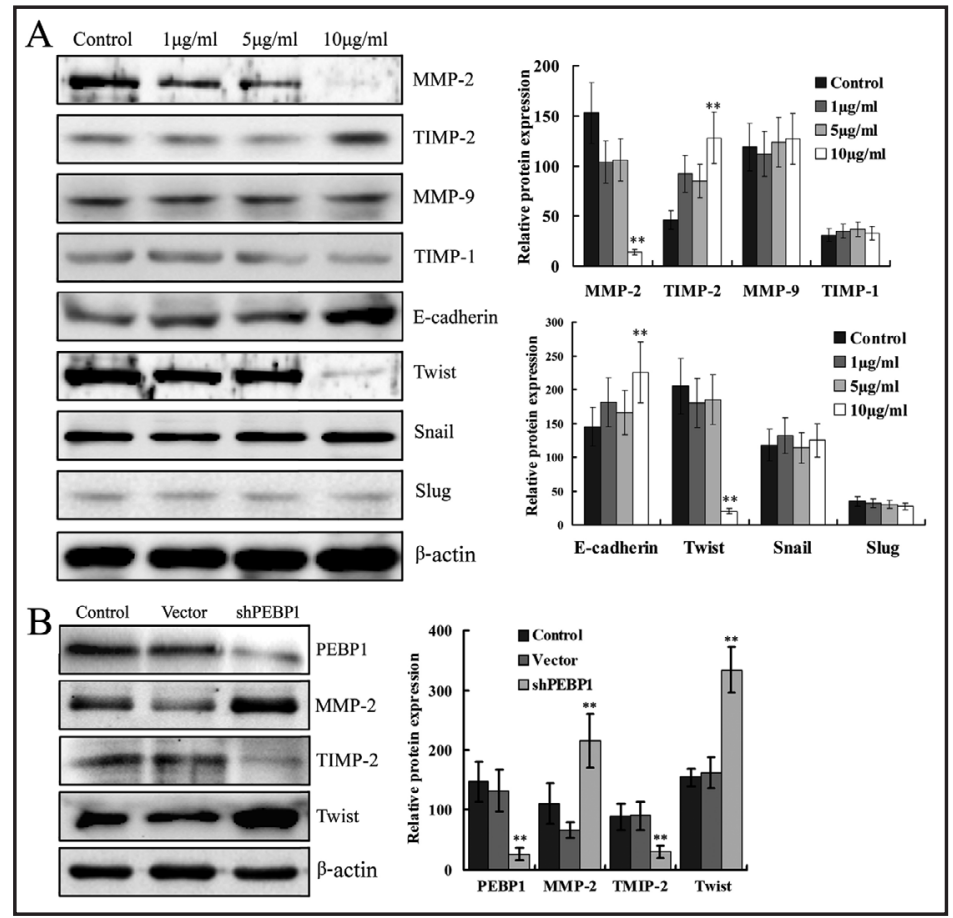


of MMP-2, TIMP-2 and Twist after treatment with shPEBP1 was detected. With PEBP1 being downregulated, MMP-2 and Twist were upregulated, and TIMP-2 was downregulated (Fig. $2 \mathrm{~B})$. These findings suggest that octreotide may inhibit tumor invasion and metastasis through a limited pathway.

\section{Octreotide upregulates PEBP1}

Based on our previous research, we assumed that octreotide would upregulate PEBP1, which is better known as RKIP [14]. The results of western blotting (Fig. 3A) confirmed that the expression of PEBP1 was significantly upregulated when the concentration of octreotide reached $10 \mu \mathrm{g} / \mathrm{ml}$. Octreotide may reduce the probability of invasion and metastasis in SKHep-1 cells by upregulating PEBP1. PEBP1 has been widely studied as a suppressor of tumor metastasis in many types of tumors [15]. Similarly, we observed lower expression of PEBP1 in highly invasive liver cancer cell line SK-Hep-1 and MHCC-97H as compared to minimally invasive cell line HepG2 and Huh7(Fig. 3B).

\section{Downregulation of PEBP1 counteracts the effect of octreotide}

To confirm that octreotide inhibited invasion and metastasis in HCC by upregulating PEBP1, a PEBP1 knockdown HepG2 cell line was constructed. As shown in Fig. 4A, the expression of PEBP1 was significantly downregulated after cells were infected with lentivirus carrying PEBP1 shRNA (shPEBP1). After the addition of octreotide to control and shPEBP1 liver cancer HepG2 cells, western blotting and transwell migration and wound-healing assays were performed to study the effects on liver cancer cells. As shown in Fig. 4B, PEBP1 was upregulated after treatment with octreotide and downregulated in shPEBP1 knockdown HepG2 cells. However, the expression of PEBP1 was not upregulated after octreotide was administered to shPEBP1 knockdown HepG2 cells. The results of the transwell migration and wound-healing assays showed that octreotide did not alter the invasion and migration ability of HepG2 cells after PEBP1 knockdown (Fig. 4C). These results indicate that octreotide reduces the invasion and migration ability of liver cancer cells through the PEBP1 pathway.

\section{Octreotide inhibits SK-Hep-1 invasion in an in-vivo model of pulmonary metastasis}

Over the course of the experiment, OT mice became increasingly heavy, with an average weight of $23 \mathrm{~g}$. In the control group, mice became heavier during the first month, but weights then declined quickly (final average weight $=16 \mathrm{~g}, \mathrm{P}<0.001$ compared to control) (Fig. 5B). After octreotide treatment, the fluorescence intensity of SK-Hep-1/Luc was detected by multimode reader as much higher than that observed in the control group (Fig. 5A). Invivo bioluminescence imaging revealed stronger fluorescence in the lungs of control vs. OT

Fig. 3. PEBP1 protein expression as measured by western blot. A, Expression of PEBP1 in SKHep-1 cells exposed to different concentrations of octreotide. B, PEBP1 protein expression in SKHep-1, MHCC-97H, HepG2, HuH7 and SMMC-7721 cells, as evaluated by western blotting. Compared to the minimally invasive cell lines HepG2 and HuH7, the PEBP1 expression of high invasive cell lines SK-Hep-1 and MHCC$97 \mathrm{H}$ was significantly lower. All experiments were repeated in triplicate. ${ }^{* *} \mathrm{P}<0.001$.

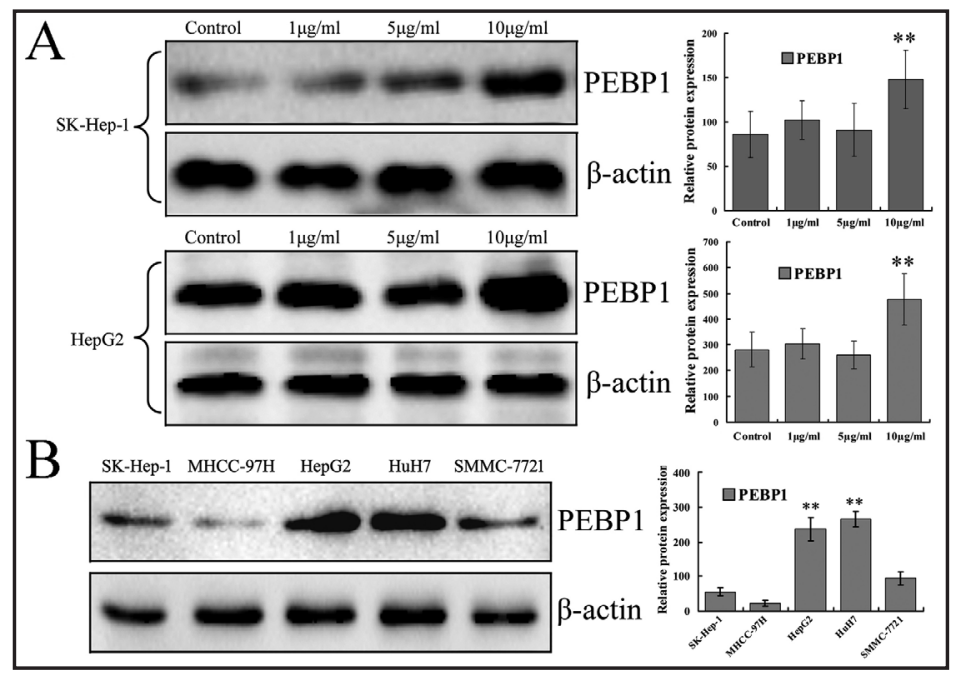


mice (Fig. 5C), suggesting less lung metastasis in the OT mice compared with controls. Not only that, metastatic human hepatoma cells were identified by H\&E staining at the juncture between the front paw and the chest in 3 of 6 control mice (Fig. 5D) but not in the OT group. All samples of lung tissue from the control group displayed erosion, unclear boundaries, and multiple nodules, but only 2 of 6 mice in the OT group exhibited similar changes (Fig. 5E). H\&E staining (Fig. 5E) of pulmonary tissue from the OT group revealed interstitial congestion but no tumor nodules. Samples from the control group displayed intravascular tumor thrombi, necrotic tissue, lymph cell infiltration, and multiple nodules in the pulmonary capsule. H\&E staining confirmed that the lung metastatic lesions were human HCC. Then, the mice lung tissues were ground and detected the expression of PEBP1 by western blot. Compared to the control group, the expression of PEBP1 in the lung tissues of OT group mice was significantly increased, indicating that not only in vitro, but also in vivo, octreotide could increase the

Fig. 4. Downregulation of PEBP1 in HepG2 cells and its effect on changes induced by octreotide. A, Fluorescence microscopy showed $90 \%$ lentivirus infection efficiency. Western blotting revealed significantly downregulated PEBP1 expression after lentivirus infection. B, Changes in PEBP1 expression after treatment with shPEBP1 and octreotide, as shown by western blotting. C, Changes in migration after treatment with ShPEBP1 and octreotide, as revealed by (a) wound-healing assay and (b) transwell migration assay. Data presented as mean \pm SD of three experiments. ${ }^{*} \mathrm{P}<0.05$, ** $\mathrm{P}<0.001$.

Fig. 5. Octreotide inhibited metastasis of HCC cells in vivo. A, Detection of bioluminescence intensity of control SK-Hep-1 and SK-Hep-1/Luc cells by multimode reader. $\mathrm{B}$, Changes in body weight for the control and octreotidetreatment (OT) group. C, In-vivo bioluminescence imaging of nude mice. D, Representative axillary lymph node metastatic tumor from the control group (H\&E staining). E, Pulmonary anatomy in nude mice and corresponding H\&E staining. F, The expression of PEBP1 in the lung tissues of mice by western blot. G, The survival curve of the mice observed for 90 days. ${ }^{*} \mathrm{P}<0.05,{ }^{* *} \mathrm{P}<0.001$.
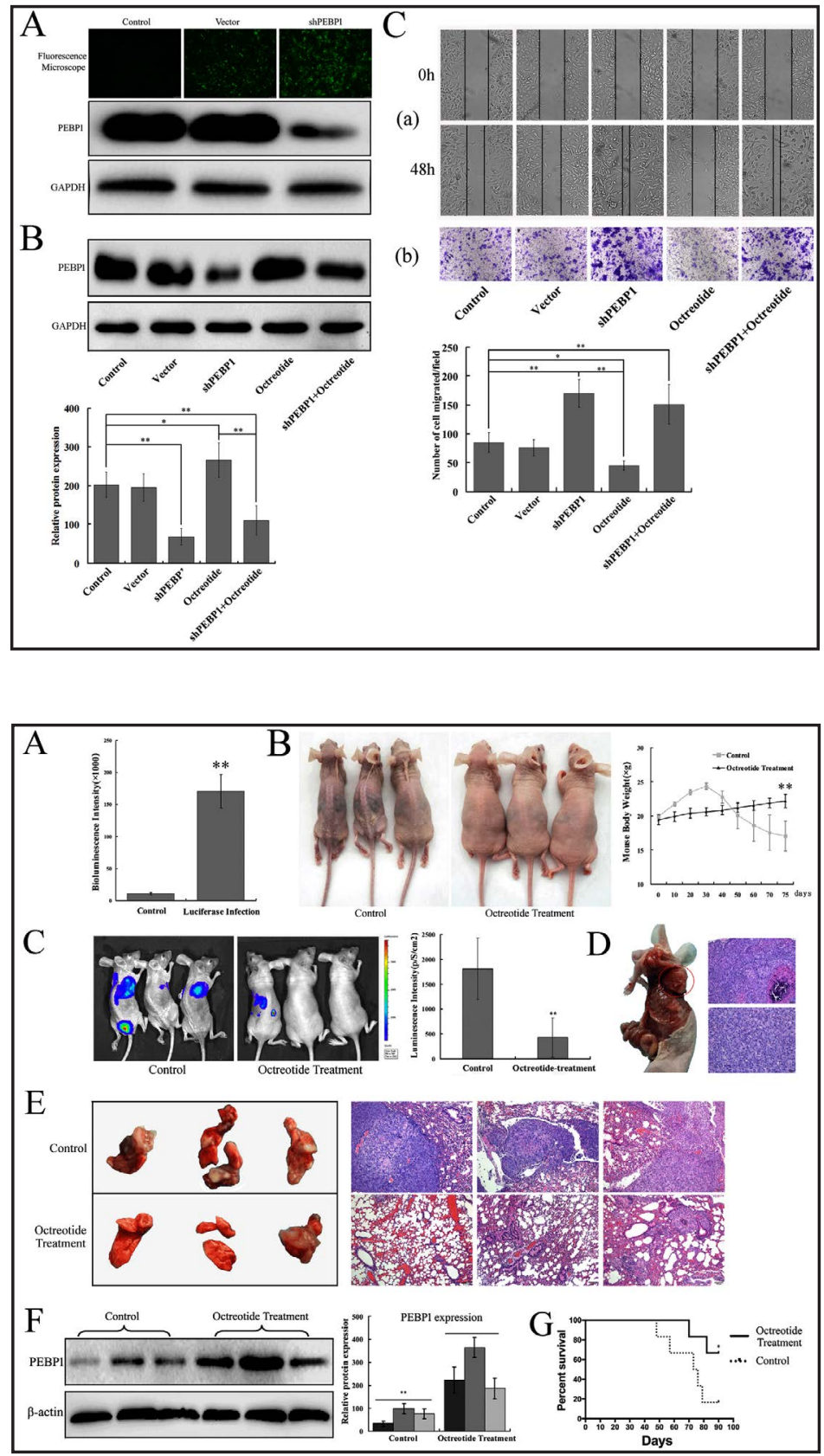
expression of PEBP1 (Fig. 5F). Meanwhile, the statistical analysis of mice survival period also showed that the survival time of the OT group mice was much longer than that of the control group (Fig. 5G). These findings indicate that octreotide may inhibit the metastasis of HCC in vivo.

\section{Discussion}

At present, the treatment of HCC typically involves surgical resection (including liver transplantation) in combination with a therapeutic regimen. During liver resection, hepatic blood flow is often occluded in order to control bleeding. Most surgeons perform selective semi-hepatic blood flow occlusion when possible [16], but extensive hepatic cancer may require excision of the whole liver block, which inevitably leads to ischemia reperfusion (IR) injury $[17,18]$.

In our previous studies [19], IEF/SDS-PAGE was used to analyze differential protein expression among patients undergoing surgery for liver cancer. Samples were obtained $15 \mathrm{~min}$ before and after hepatic IR. We found that under the condition of IR stress, tumor metastasis suppressor gene PEBP1 was significantly downregulated. PEBP1 maybe one of the first anti-oncogenes to be downregulated, which may be one of the factors that facilitates the invasion and metastasis of tumor cells after IR injury. We comparatively analyzed the mitochondrial proteins in HCC and non-cancerous tissues by two-dimensional gel electrophoresis, which revealed that the expression of PEBP1 was significantly lower in cancer tissues [20]. Therefore, a drug targeted to PEBP1 may be useful to reduce the recurrence and metastasis of liver cancer after surgery.

PEBP1 is also known as RKIP, which is a serine protease inhibitor. RKIP can inhibit the activity of MAPK signaling through interaction with Raf-1, and is also involved in regulating PKC, G-protein-coupled receptors, and the NF- $\kappa B$ pathway [21]. Because PEBP1 can inhibit tumor metastasis, it is also considered a tumor suppressor gene [15].

We speculated that octreotide may work in hepatic IR, not only protecting against liver IR injury but also reducing the risk of postoperative tumor metastasis. One study [22] on the treatment of pancreatic cancer with octreotide showed that the liver function of patients who received octreotide was significantly improved (total survival increased from 7.3 to 12.3 months, compared to the control group). The use of octreotide marked with a radioactive element to treat neuroendocrine tumors is currently being investigated [23]. Several studies have found that octreotide could be used to treat neuroendocrine tumors [24] and duodenal adenocarcinoma [25], and it may reduce liver metastasis. Octreotide may induce morphological changes and mitochondrial vacuolization that trigger apoptosis in liver cancer cells [26]. Octreotide could inhibit the recurrence and metastasis of liver cancer cells by inhibiting angiogenesis.

We therefore studied the effect of octreotide on HCC cell lines HepG2 and SK-Hep-1. We administered octreotide to cultured cells at concentrations of 1,5 , or $10 \mu \mathrm{g} / \mathrm{ml}$ (more than 10 times the clinical dosage). The results of the wound-healing and transwell invasion and migration assays confirmed that $10 \mu \mathrm{g} / \mathrm{ml}$ of octreotide impaired the invasion and transfer ability of HCC cells.

PEBP1 expression was significantly lower in the highly invasive HCC cell line SK-Hep-1 as compared to the minimally invasive HCC cell line HepG2. The expression of PEBP1 increased significantly with increasing octreotide concentrations in SK-Hep-1 cells. Hence, octreotide may inhibit invasion and metastasis in HCC.

We further studied changes in the levels of tumor invasion and metastasis-related signaling molecules after the addition of octreotide. MMPs are zinc-dependent endopeptidases involved in the degradation of extracellular matrix (ECM), and thus promote tumor metastasis [27]. Our results suggested that octreotide might regulate the MMP2-TIMP2 pathway (but not the MMP9-TIMP1 pathway) to influence cell invasion and metastasis. Proteins such as E-cadherin, Twist, slug and snail participate in the epithelial-mesenchymal transition (EMT), 
which is an important part of tumor progression and metastasis [28]. EMT-related markers such as E-cadherin and EMT transcription factors such as Twist, snail, and slug are important indicators of alterations to the EMT. Our results suggest that octreotide inhibits Twist and thus upregulates E-cadherin to alter the EMT. Recent research [29] has also shown that MMP2 may influence invasion through direct interaction with Twist. The effects of octreotide may therefore be mediated through a PEBP1-TIMP2-MMP2-Twist pathway.

To investigate whether octreotide affects the invasion and metastasis of HCC through the PEBP1 pathway, octreotide was added to the PEBP1 knockdown liver cancer cells. No effect was observed, supporting our hypothesis. Furthermore, by establishing a pulmonary metastasis animal model, we verified the inhibitory effect of octreotide on the invasion and metastasis of HCC cells in vivo.

Octreotide appears to reduce invasion and metastasis through the upregulation of PEBP1. While octreotide had been used to reduce hepatic IR injury in the clinic, this study showed that octreotide may also reduce the risk of post-operative recurrence and metastasis of HCC. Octreotide may represent a new tool with which to reduce the risk of recurrence and metastasis after surgery in patients with liver cancer.

\section{Acknowledgements}

This work was supported by the National Clinical Key Specialty Construction Program, Key Clinical Specialty Discipline Construction Program of Fujian, National Health and Family Planning Commission Research Fund-United Fujian Provincial Health and Education Project (Grant No. WKJ-FJ-04).

\section{Disclosure Statement}

The authors declare to have no conflict of interests.

\section{References}

1 Torre LA, Bray F, Siegel RL, Ferlay J, Lortet-Tieulent J, Jemal A: Global cancer statistics, 2012 CA Cancer J Clin 2015;65:87-108.

2 El-Serag HB, Rudolph KL: Hepatocellular carcinoma: epidemiology and molecular carcinogenesis. Gastroenterology 2007;132:2557-2576.

- 3 Lu X, Zhao HT, Mao YL, Sang XT, Xu YY, Du SD, Xu HF, Chi TY, Yang ZY, Zhong SX, Huang JF: Early recurrence after the resection of hepatocellular carcinoma. Zhongguo Yi Xue Ke Xue Yuan Xue Bao 2008;30:415-420.

4 Biswas S, Guix M, Rinehart C, Dugger TC, Chytil A, Moses HL, Freeman ML, Arteaga CL: Inhibition of TGF-beta with neutralizing antibodies prevents radiation-induced acceleration of metastatic cancer progression. J Clin Invest 2007;117:1305-1313.

5 Martin OA, Anderson RL, Narayan K, MacManus MP: Does the mobilization of circulating tumour cells during cancer therapy cause metastasis? Nat Rev Clin Oncol 2017;14:32-44.

-6 Sawabata N, Funaki S, Hyakutake T, Shintani Y, Fujiwara A, Okumura M: Perioperative circulating tumor cells in surgical patients with non-small cell lung cancer: does surgical manipulation dislodge cancer cells thus allowing them to pass into the peripheral blood? Surg Today 2016;46:1402-1409.

7 Dahaba AA, Mueller G, Mattiassich G, Rumpold-Seitlinger G, Bornemann H, Rehak PH, Linck G, Mischinger HJ, Metzler H: Effect of somatostatin analogue octreotide on pain relief after major abdominal surgery. Eur J Pain 2009;13:861-864.

8 Kurnatowska I, Pawlikowski M: Anti-inflammatory effects of somatostatin analogs on zymosan-induced earlobe inflammation in mice: comparison with dexamethasone and ketoprofen. Neuroimmunomodulation 2001;9:119-124.

9 Chowers Y, Cahalon L, Lahav M, Schor H, Tal R, Bar-Meir S, Levite M: Somatostatin through its specific receptor inhibits spontaneous and TNF-alpha- and bacteria-induced IL-8 and IL-1 beta secretion from intestinal epithelial cells. J Immunol 2000;165:2955-2961. 


\section{Cellular Physiology Cell Physiol Biochem 2018;47:2340-2349

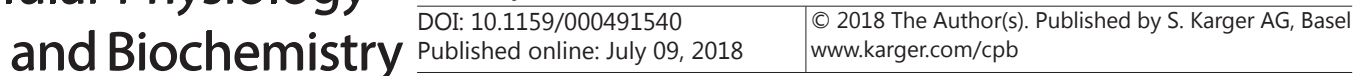

Huang et al.: Octapeptide Inhibits Metastasis of HCC by PEBP1

10 Demirkan BH, Eriksson B: Systemic treatment of neuroendocrine tumors with hepatic metastases. Turk J Gastroenterol 2012;23:427-437.

11 Yang F, Wu H, Li Y, Li Z, Wang C, Yang J, Hu B, Huang Z, Ji R, Zhan X, Xie H, Wang L, Zhang M, Tang C: Prevention of severe acute pancreatitis with octreotide in obese patients: a prospective multi-center randomized controlled trial. Pancreas 2012;41:1206-1212.

12 Yamamoto K, Takenaka K, Matsumata T, Shimada M, Sugimachi K: The effect of octreotide on morphological hepatic regeneration and hepatic functional recovery after a two-thirds hepatectomy in rats.

Hepatogastroenterology 1999;46:1880-1884.

13 Woeste G, Wullstein C, Meyer S, Usadel KH, Hopt UT, Bechstein WO, von Dobschuetz E: Octreotide attenuates impaired microcirculation in postischemic pancreatitis when administered before induction of ischemia. Transplantation 2008;86:961-967.

14 Noh HS, Hah YS, Zada S, Ha JH, Sim G, Hwang JS, Lai TH, Nguyen HQ, Park JY, Kim HJ, Byun JH, Hahm JR, Kang KR, Kim DR: PEBP1, a RAF kinase inhibitory protein, negatively regulates starvation-induced autophagy by direct interaction with LC3 Autophagy 2016;12:2183-2196.

15 Lamiman K, Keller JM, Mizokami A, Zhang J, Keller ET: Survey of Raf kinase inhibitor protein (RKIP) in multiple cancer types. Crit Rev Oncog 2014;19:455-468.

16 Li M, Zhang C, Zhang T, Wang L, Ding Y, Niu Z, He S, Yang Z: Outcome using selective hemihepatic vascular occlusion and Pringle maneuver for hepatic resection of liver cavernous hemangioma. World J Surg Oncol 2015;13:267.

17 Gibelin H, Eugene M, Hebrard W, Henry C, Carretier M, Hauet T: A new approach to the evaluation of liver graft function by nuclear magnetic resonance spectroscopy. A comparative study between Euro-Collins and University of Wisconsin solutions. Clin Chem Lab Med 2000;38:1133-1136.

18 Chung KY, Jeong GY, Choi KB, Sung SH, Kim YS: Prevention of primary nonfunction after canine liver allotransplantation: the effect of gadolinium chloride. Transplant Proc 2004;36:1928-1930.

19 C.Z. H, K.C. L, B. W, A.M. H, H.J. C, X. T, J.F. L, Y.B. Y: Differential proteomic research of liver ischemiareperfusion injury undergo resection of hepatocellular carcinomas. Journal of Clinical Rehabilitative Tissue Engineering Research 2012;24:7539-7543.

-20 Ye Y, Huang A, Huang C, Liu J, Wang B, Lin K, Chen Q, Zeng Y, Chen H, Tao X, Wei G, Wu Y: Comparative mitochondrial proteomic analysis of hepatocellular carcinoma from patients. Proteomics Clin Appl 2013;7:403-415.

21 Yeung K, Seitz T, Li S, Janosch P, McFerran B, Kaiser C, Fee F, Katsanakis KD, Rose DW, Mischak H, Sedivy JM, Kolch W: Suppression of Raf-1 kinase activity and MAP kinase signalling by RKIP. Nature 1999;401:173177.

-22 Zheng D, Huang X, Fan Y, Liao Y, Zhang H, Wang P, Wu J: The effect of octreotide treatment on patients with pancreatic cancer who undergo endoscopic retrograde cholangiopancreatography (ERCP) with pancreatic duct stent placement. Hepatogastroenterology 2013;60:222-224.

23 Hanna M, Mikko T: [Radionuclide therapy for cancer--what's new?]. Duodecim 2012;128:2209-2216.

24 Fischbach J, Gut P, Matysiak-Grzes M, Klimowicz A, Gryczynska M, Wasko R, Ruchala M: Combined octreotide and peptide receptor radionuclide therapy ((90)Y-DOTA-TATE) in case of malignant insulinoma. Neuro Endocrinol Lett 2012;33:273-278.

-25 Kato K, Takeshita Y, Misu H, Ishikura K, Kakinoki K, Sawada-Kitamura S, Kaneko S, Takamura T: Duodenal adenocarcinoma with neuroendocrine features in a patient with acromegaly and thyroid papillary adenocarcinoma: a unique combination of endocrine neoplasia. Endocr J 2012;59:791-796.

26 Yang J, Sun H, Guan R, Liu W, Xia Y, Zhao J, Liu J: Hepatocellular protein profiles after hepatic ischemia/ reperfusion injury with or without octreotide preconditioning in a rabbit model. Transplant Proc 2014;46:3282-3288.

27 Bager CL, Willumsen N, Leeming DJ, Smith V, Karsdal MA, Dornan D, Bay-Jensen AC: Collagen degradation products measured in serum can separate ovarian and breast cancer patients from healthy controls: A preliminary study. Cancer biomarkers : section A of Disease markers 2015;15:783-788.

28 Mitra A, Yan J, Xia X, Zhou S, Chen J, Mishra L, Li S: IL6 mediated inflammatory loop reprograms normal to EMT+ metastatic CSCs in pre-neoplastic liver of TGFbeta deficient beta2SP+/- mice. Hepatology 2016

-29 Rahme GJ, Israel MA: Id4 suppresses MMP2-mediated invasion of glioblastoma-derived cells by direct inactivation of Twist1 function. Oncogene 2015;34:53-62. 